\title{
The Emotional Leadership of Managers Applied to University Teaching Role
}

\author{
Beatriz Peña Acuña* \\ Education and Business Department \\ Catholic University of Saint Anthony \\ Guadalupe 30107, Murcia, Spain \\ bpena@ucam.edu \\ *Corresponding author
}

\author{
Gonzalo Wandosell Fdez de Bobadilla* \\ Dean of Business Department \\ Catholic University of Saint Anthony \\ Murcia, Spain \\ gwandosell@ucam.edu \\ *Corresponding author
}

\begin{abstract}
Long time ago in 1995 Daniel Goleman surprises Business and Education fields with the concept of emotional intelligence but there is still a long way to go on. This text exposes an innovative field of research and training that changes the traditional model of Education highlighting socio-emotional skills in order to adapt socially and professionally: the need of research and train in emotional and social intelligence in teaching university staff and in emotional leadership (a business and managerial concept), a broader and more ambitious project.
\end{abstract}

Keywords-emotional intelligence; social intelligence, resonant leadership; training university teaching staff

\section{INTRODUCTION}

From that emotional intelligence is disseminated through the book Emotional Intelligence by Daniel Goleman (1995), US research studies in human resources of the company for almost 20 years have shown to be a factor of professional success in $80 \%$ of cases, adaptation to the work teams and business changes and anticipate spending conflict management. A Spanish researcher, Nieves Segovia, states that according to "The Consortium for Research Emotional Intelligence in Organizations" successful people they owe by $23 \%$ to the intellectual, and $77 \%$ to the emotional skills.

In addition we discovered that emotional and social intelligence is being implemented in many educational systems such as CASEL (Collaborative for academic, social and emotional learning) in North America's schools with funding from the Rockefeller Foundation or the Spanish laws of several autonomies as basic training for children and adolescents. According to Goleman emotional intelligence means (1995) the skill acquired and also appears as a feature profile in individuals who are aware of their own emotional world; they also know specifically who to identify what type of emotion overwhelms them, they know how effectively manage the face of difficulties, and have emotional balance. They also tend to be empathetic with others, have the advantage of knowing how to give good advice on the emotional field to others and know how to manage conflicts in social life.

\section{RESONANT LEADERSHIP AND SOCIAL INTELLIGENCE}

Then Daniel Goleman continued researching the business field and the resonant states (emotional) of leadership and he published a book about it in 2002 and about the social intelligence in 2008.

\section{A. Resonant Leadership}

Boyatzis, Goleman and McKee announced the resonant (or emotional) leadership understood that the most vocal people are those who tune better with others and maintaining transparent relations, because the resonance minimize system noise. This group leadership shows social and emotional skills. For Daniel Goleman lead is an emotional task. Meanwhile, Goleman and Boyatzis (2002) emotions are open circuit from the emotional stability that depend on the relationships we build with others unlike other body systems are a closed circuit, that is a reason to understand the importance of the leader, his actions and how they influence the organization. Therefore we defend that the teaching role must deploy a resonant leadership that can recognize their own feelings and those of others, ie those of their students, and must possess the ability to manage and get a harmonic tuning group, in this case with the aim of instill a deep motivation in students who perceive that what makes as useful and necessary for their development in society seeking a climate of optimistic, cheerful and personal enrichment classroom.

Recent research of Extremera and Berrocal (2004) in schools has found important results that analyze the EI students. These findings associated low levels of IE with less wellness in students, reduced and poor social relationships, lower academic achievement, truancy, studies failure, disruptive and addictive behaviors. To teach how to manage emotions it seems to be effective instruction, but rather, roleplaying, modeling and exploiting the interaction, these techniques seem to be more appropriate when dealing with skills that one must learn and be trained on. Indeed, educators are in line with the above, models for students desirably should self-regulate their emotions as experts to teach by example to others.

There are also studies of Duran, Extremera and Rey about emotional intelligence in teachers that discovered that the ones with more level of this factor they show less anxiety, stress, depression, anger and burnout (2001). 


\section{B. Social Intelligence}

The social intelligence that Goleman exposes it is based on three axes as how to be empathetic, knowing treat others and develops social sensitivity. Be empathetic can be understood as the quality of get into the skin of others and understand other subjective views and different from oneself. Learn to treat others is an aspect that allows us to be respectful, cordial, maintain an assertive style and know dealing with conflicts. Social sensitivity is an ability to perceive the needs of others and their social environment and be practical in finding solutions. Usually altruistic people engaged with society, actively collaborate with NGOs and with the poor.

Hernandez (2000) emphasizes that the school has gone from being a place to learn to be a place to learn to think and live. Here we focus on how to live in society as a basic learning to acquire and adapt socially and professionally and maintain it. At present they are carrying out various educational projects in Spain as shown by Manuel Segura on social competence In Primary (relate well) and Secondary (being a person and relate) in the Canary Islands and subsequently in Catalonia (Spain, Europe). We have also researched recently with qualitative methodology the need of social intelligence in teachers of Primary and Secondary (see Social intelligence: Research in Primary and Secondary teachers Wandosell, Peña, Parra- Vision libros publishing in 2014).

Lopez et al (1999) expose, from the evolutionary psychology, the question of emotional development and social aspect, and, in particular the pedagogical intervention of socioemotional growth.

In theory of Education it had gave importance to the training of social skills at an earlier stage to the attention of emotional intelligence. In that way Goldstein and Michaelson are milestones publications. They have also appeared programs and studies such as Caballo, Gil y Leon, Moraleda and Trianes et al. In many of these technical training programs aimed social success and assertiveness. Manuel Segura says that the failures of these programs are due to incomplete in the case of social skills moral growth was neglected.

\section{INNOVATION THROUGH APPLYING RESONANT LEADERSHIP TO SPECIFIC TRAINING TEACHERS}

In terms of leadership, managers have emotional leadership "de facto" because they guide employees as a conductor raising objectives, goals. The most innovative idea of our proposal it is applying it to university teaching level. It is a new area of training and research. It is not only talking about emotional and social intelligence in Primary or Secondary students or teachers as it has been researched but it is talking about the need of training in emotional and social intelligence in teaching university staff and in emotional leadership, a broader and more ambitious project.

We believe that a university teaching role also serves as guide for students because their wills, reason, efforts, so if the lecturer is in a bad mood, he creates a tense working environment and students are afraid to ask; on the contrary, I he knows how to dispense humor, if he is cheerful, close and friendly the students can learn up to seven times; he makes them kind the field of study he introduces and motivates to investigate and entering with effort. So we think we may extend resonant leadership of a steering a teacher, as both exert a kind of emotional leadership also.

For our part during some years we have made many field studies on the variables we propose and implement innovative ways that have been related. We are convinced that the main wealth and value for performance and productivity of a company is the staff and how they are organized and people coexist.

From the Spanish research group called Personal Development we design a $\mathrm{R} \& \mathrm{D}$ project for companies that offers implement in companies that are dedicated to HR, recruitment of staff or consulting a tool for the selection of staff attending to emotional aspects and socio-emotional or assessment and educational programming.

We are also natively developing training and educational innovation university teaching staff projects in emotional skills so as we understand it can be also transferred the concept of resonant leadership formulated in business area in the field of Education where the teaching role should be aware of the importance of creating an environment conducive to learning and motivation to make the learning experience with an added value- over the traditional model emotional climate- in which the learning process becomes a discovery of cooperation and mutual enrichment by satellite a pleasant social life and which are carried out proper management of conflicts.

We understand motivation as the driving force that directs the activities of individuals to achieve a goal, in this case it can be applied to the desire of students to learn to be both internal motivation and the external (running in part by Lecturers and Professors). Motivation is a term that is closely related to EI and the process of teaching and learning because a person who has that intelligence is better known, is able to motivate more and traced a failure looking for other activities that encourage and have a the joy out of sorrow involved a failure or frustration. Motivation is an issue that has gained interest in the field of Educational Psychology at which arises from homeostatic explanations made by Cannon in 1932 to attribution theory of Weiner in 1992. It has also taken into account as an important factor to be taken into account as effective leadership skills and human resource management in the business field recently.

Classroom climate is a term the educational environment arising from the terminology of interaction (a term which in turn is rooted in studies of Psychology and Psychiatry at the 30 s in XX century. Sampascual defines this term like "atmosphere or different climate that arises from the dominant tone of the emotional experiences of its members, and has been associated with the type of personal interactions between the student and the teacher and among students [1]". We understand that teaching effectiveness is due to training acquired by the teacher teaching through techniques and professional experience with human material to make students understand and come to acquire the attitudes, content and desired skills. 
ACKNOWLEDGMENT

“K.W., G. A., G.P.P., M.M.ANEP thanks”.
REFERENCES

[1]Sampascual. Guide of Psicology of Education. Madrid:UNED. pp.328-329. 